\title{
Influence of delayed pouring on irreversible hydrocolloid properties
}

\author{
Stéfani Becker Rodrigues \\ Carolina Rocha Augusto \\ Vicente Castelo Branco Leitune \\ Susana Maria Werner Samuel \\ Fabrício Mezzomo Collares
}

Dental Materials Laboratory, School of Dentistry, Univ Federal do Rio Grande do Sul - UFRGS, Porto Alegre, RS, Brazil.
Declaration of Interests: The authors certify that they have no commercial or associative interest that represents a conflict of interest in connection with the manuscript.

\section{Corresponding Author:}

Fabrício Mezzomo Collares

E-mail: fabricio.collares@ufrgs.br

Submitted: May 07, 2012

Accepted for publication: Jun 26, 2012

Last revision: Jul 12, 2012

\begin{abstract}
The aim of this study was to evaluate the physical properties of irreversible hydrocolloid materials poured immediately and after different storage periods. Four alginates were tested: Color Change (Cavex); Hydrogum (Zhermack); Hydrogum 5 (Zhermack); and Hydro Print Premium (Coltene). Their physical properties, including the recovery from deformation $(\mathrm{n}=3)$, compressive strength $(\mathrm{n}=3)$, and detail reproduction and gypsum compatibility $(\mathrm{n}=3)$, were analyzed according to ANSI/ ADA specification no. 18 . Specimens were stored at $23^{\circ} \mathrm{C}$ and humidity and were then poured with gypsum immediately and after 1, 2, 3, 4, and 5 days. The data were analyzed by two-way analysis of variance (ANOVA) and Tukey's test at $p<0.05$. All of the alginate impression materials tested exhibited detail reproduction and gypsum compatibility at all times. Hydro Print Premium and Hydrogum 5 showed recovery from deformation, as established by ANSI/ADA specification no. 18, after 5 days of storage. As the storage time increased, the compressive strength values also increased. Considering the properties of compounds' recovery from deformation, compressive strength, and detail reproduction and gypsum compatibility, irreversible hydrocolloids should be poured immediately.
\end{abstract}

Descriptors: Dental Impression Materials; Compressive Strength; Calcium Sulfate.

\section{Introduction}

Due to their low cost and easy handling, irreversible hydrocolloids are one of the most commonly used impression materials in dental practice. Currently, they are more commonly used for initial impressions to obtain a preliminary model used for diagnostic purposes, treatment planning, and fabrication of provisional prostheses or custom trays. ${ }^{1}$

The alginate impression materials contain sodium alginate, calcium sulfate, trisodium phosphate, diatomaceous earth, zinc oxide, and potassium titanium fluoride, all in the form of a powder. When mixed with water, a sol is formed through a reaction with the sodium or potassium salts of alginic acid and calcium sulfate. After this chemical reaction takes place, a fast-setting gel is formed as a result of the replacement of the monovalent calcium by sodium and potassium cations, allowing crosslinking of the alginic salts. ${ }^{2,3}$ There are many commercial variations of alginate that vary in consistency, setting time, elasticity, strength, and dimensional stability; manufacturers also add fillers, which can present an impact on its properties, application, setting time, and pouring time. ${ }^{2}$ 
The physical, mechanical, and chemical properties of alginate can be affected by how long they are stored and by the storage conditions prior to the production of the gypsum cast. ${ }^{4}$ Compared to other impression materials, irreversible hydrocolloids have the disadvantages of low dimensional stability and reduced capacity for detail reproduction. ${ }^{5}$ Dental casts obtained from impressions made with irreversible hydrocolloids tend to present decreased detail reproduction, particularly in sharp line-angle areas, ${ }^{6}$ compared to those from other impression materials, such as elastomers. The dimensional stability of alginate is required to obtain reliable gypsum models of the molded arches. ${ }^{7}$ It is recommended that irreversible hydrocolloid impressions be poured immediately or within a few minutes of removal from the mouth to prevent distortion. ${ }^{8}$ Syneresis or imbibition when exposed to air or water ${ }^{7}$ could influence alginate's dimensional stability, leading to less accurate casts. ${ }^{2}$ To overcome this problem of a short recommended pouring time after impression, new irreversible hydrocolloids have been developed with increased pouring times, even allowing for up to five days of storage. Because pouring time is an important factor in the dimensional stability of irreversible hydrocol- loids and the resulting stone casts, an investigation of these new materials is needed. The aim of this study was to evaluate the properties of irreversible hydrocolloid impression materials poured immediately and after specific storage periods.

\section{Methodology}

This study was conducted at the Laboratory of Dental Materials at the Federal University of Rio Grande do Sul, and it was approved by the Research Committee. Three irreversible hydrocolloid extended-pour products, Hydrogum 5 (Zhermack, Badia Polesine, Italy), Hydro Print Premium (Vigodent Coltene, Rio de Janeiro, Brazil), and Color Change (Cavex, Haarlen, Netherlands), were compared with the conventional irreversible hydrocolloid Hydrogum (Zhermack, Badia Polesine, Italy) (Table 1). The storage times tested were $0,1,2,3,4$, and 5 days. All materials were handled in accordance with the manufacturer's instructions and stored with humidity in a sealed plastic bag. ${ }^{2,5}$ The sample size, parameters to reproduce detail, compatibility with gypsum, recovery of deformation, and compressive strength were analyzed in accordance with the ANSI/ADA specification no. $18 .^{9}$ The specimens were measured

\begin{tabular}{|c|c|c|c|c|}
\hline \multirow{6}{*}{$\begin{array}{r}\text { Table } 1 \text { - Materials, } \\
\text { manufacturers, composition, and } \\
\text { lot number of the impression } \\
\text { materials. }\end{array}$} & Materials & Manufacturer & Composition & Lot number \\
\hline & Hydrogum & Zhermack SpA, Italy & $\begin{array}{l}\text { Potassium alginate, diatomaceous } \\
\text { earth, calcium sulfate, trisodium } \\
\text { phosphate, triaminofunctional silane }\end{array}$ & 103291 \\
\hline & $\begin{array}{l}\text { Hydroprint } \\
\text { Premium }\end{array}$ & Coltene, Switzerland & $\begin{array}{l}\text { Potassium alginate, calcium sulfate } \\
\text { hemihydrate, diatomaceous } \\
\text { earth, magnesium oxide, tetra } \\
\text { sodium pyrophosphate, potassium } \\
\text { fluorotitanate, propylene glycol }\end{array}$ & 1101803 \\
\hline & $\begin{array}{l}\text { Cavex } \\
\text { ColorChange }\end{array}$ & Cavex, Netherlands & $\begin{array}{l}\text { Sodium and/or potassium alginate, } \\
\text { calcium sulfate hemihydrate, } \\
\text { magnesium oxide, potassium } \\
\text { and/or sodium fluorotitanate, } \\
\text { tetra sodium and/or potassium } \\
\text { pyrophosphate, phenolphthalein, } \\
\text { magnesium silicate, thymolphthalein, } \\
\text { sodium and/or potassium silicate, } \\
\text { diatomaceous earth }\end{array}$ & 100211 \\
\hline & Hydrogum 5 & Zhermack SpA, Italy & $\begin{array}{l}\text { Potassium alginate, diatomaceous } \\
\text { earth, calcium sulfate, trisodium } \\
\text { phosphate, triaminofunctional silane }\end{array}$ & 129049 \\
\hline & $\begin{array}{l}\text { Elite Dental } \\
\text { Stone IV }\end{array}$ & Zhermack SpA, Italy & $\begin{array}{l}\text { Calcium sulfate, potassium sulfate, } \\
\text { sodium citrate }\end{array}$ & 127086 \\
\hline
\end{tabular}


(height and diameter) and weighed before and after the storage time. One operator completed the manipulation process, and another operated the universal testing machine and measured the specimens.

\section{Detail reproduction and gypsum compatibility}

The alginates were mixed and inserted into a ring mold with a diameter of $30 \mathrm{~mm}$ and a height of $6 \mathrm{~mm}$. Immediately, the assembly was placed in a water bath at $35^{\circ} \mathrm{C} \pm 1{ }^{\circ} \mathrm{C}$ and loaded with a $1-\mathrm{kg}$ mass. After 3 minutes of setting time, the assembly was removed from the water bath, and the alginate impression was separated from the ring mold. The surface was rinsed, and the excess fluid was shaken off. According to the manufacturers' instructions, the gypsum was mixed, and the cast was filled using mechanical vibration. After 30 minutes, the excess was removed, and the gypsum casts were examined under low-angle illumination at magnifications of $\times 4$ and $\times 12$. The examiner recorded whether the $50-\mu \mathrm{m}$ line was completely reproduced over the full length of $25 \mathrm{~mm}$ between the intersection lines. The detail reproduction and gypsum compatibility were considered positive if the $50-\mu \mathrm{m}$ line was fully reproduced in at least two of three casts $(n=3)$.

\section{Recovery from deformation}

The ring was placed on a glass plate that was filled with mixed alginate material. The cylindrical mold, with a diameter of $12.5 \mathrm{~mm}$ and a height of
$20 \mathrm{~mm}$, was pressed into the ring until the bottom of the mold touched the glass plate. Then, the second plate was clamped over the mold to form the upper surface of the specimen (Figure 1). Thirty seconds after the end of mixing, the cylindrical mold was placed and fixed by a C-clamp in a water bath at $35^{\circ} \mathrm{C} \pm 1^{\circ} \mathrm{C}$. After the setting time recommended by the manufacturer, the specimen $(\mathrm{n}=3)$ was separated and subjected to compression force. The applied force was sufficient to deform the height of the sample in $20 \%$. The spindle of the dial indicator was gently lowered until it came in contact with the area above the specimen, and the height $(\alpha)$ was measured with a digital caliper. The specimen was deformed to $16.0 \mathrm{~mm} \pm 1.0 \mathrm{~mm}$ within $1 \mathrm{~s}$, and this deformation was maintained for $5.0 \mathrm{~s}$. The force was removed, and the height of the specimen $(\beta)$ was recorded after $40 \mathrm{~s}$. The recovery from deformation (RD) was calculated as a percentage using the following formula:

$$
\mathrm{RD}=100 \times[1-(\alpha-\beta / 20)]
$$

where 20 is the height of the mold, $\alpha$ is the specimen's initial height and $\beta$ is the specimen's final height.

\section{Compressive strength}

The specimens $(n=3)$ were prepared as described for the test of recovery from deformation. Sixty seconds after the manufacturer's stated setting time,
Figure 1 - Schematic drawing of the procedure for obtaining specimens for recovery from deformation and compressive strength tests. The ring (A) was pressed into the cylindrical mold (B) containing alginate. After the setting time passed, the specimen

(C) was separated.

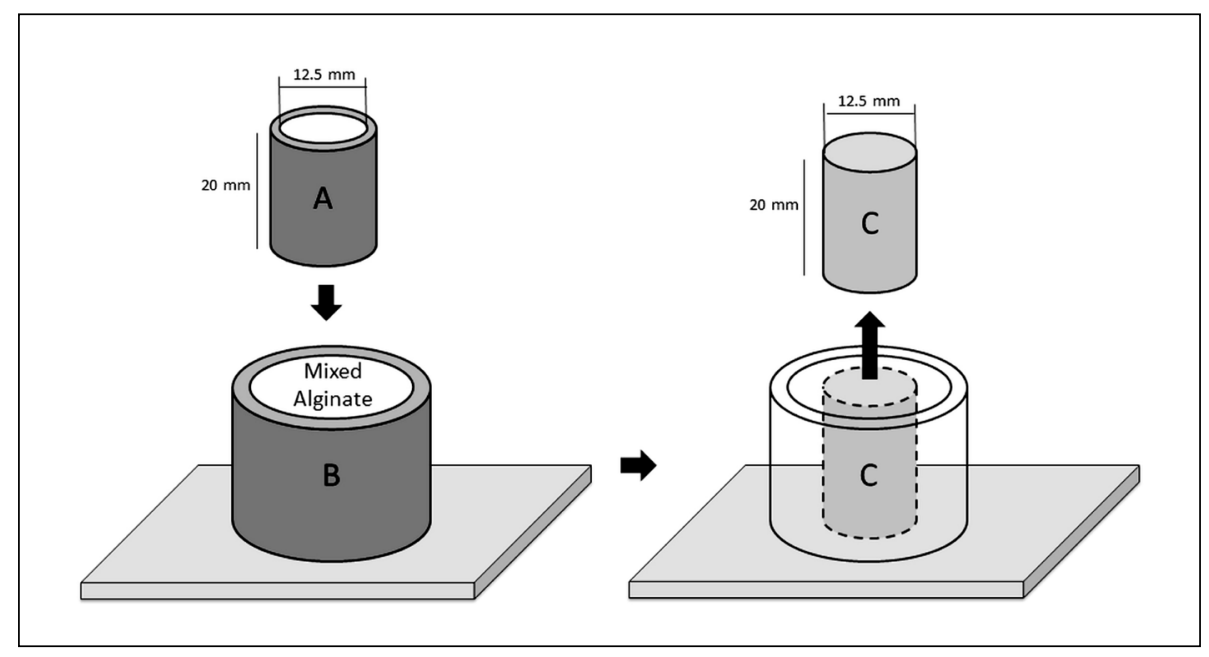


the specimen was placed, covered at both ends, between the anvils of a compressive strength-testing apparatus (DL-2000, EMIC, São José dos Pinhais, Brazil). The specimens were loaded continuously and as uniformly as possible to produce an average rate of loading of $100 \mathrm{~N} \cdot \mathrm{min}^{-1} \pm 20 \mathrm{~N} \cdot \mathrm{min}^{-1}$, until the first fracture was clearly shown on the graph. The compressive strength was calculated in megapascals using the following formula:

$$
\mathrm{K}=4 \mathrm{~F} / \pi \mathrm{d}^{2}
$$

where $\mathrm{F}$ is the force at fracture $(\mathrm{N})$ and $\mathrm{d}$ is the diameter of the test specimen $(\mathrm{mm})$.

\section{Analysis of results}

Statistical analysis was performed using SigmaStat (version 4, Ashburn, USA). The normality of the results was tested using the Kolmogorov-Smirnov test. The statistical tests used were two-way ANOVA (delayed pouring time and alginate brands) and Tukey's multiple comparison test. The significance level was 5\% for all tests.

\section{Results}

\section{Detail reproduction and gypsum compatibility}

All of the alginates analyzed in this study achieved satisfactory results for detail reproduction and gypsum compatibility after all storage periods, according to ANSI/ADA specification no. 18 .

\section{Recovery from deformation}

According to ANSI/ADA specification no. 18, the recovery from deformation should be at least 95\%. Only Hydro Print Premium and Hydrogum 5 showed results compatible with the norm after all storage periods. For ColorChange and Hydrogum, the recovery from deformation was in accordance with the standard for $0,1,2$, and 3 days and for 0 , 1 , and 2 days, respectively. All of these results are shown in Figure 2.

\section{Compressive strength}

The results of the compression strength tests are shown in Table 2. As the storage time increased, compression strength increased for all the materials tested $(\mathrm{p}<0.05)$. Cavex ColorChange exhibited lower values of compressive strength. Interactions between the factors of ANOVA were statically significant $(\mathrm{p}<0.001)$.

\section{Discussion}

Irreversible hydrocolloids are hydrophilic materials that can reproduce hard and soft tissue detail in the presence of moisture. ${ }^{2}$ Concerns about their performance include dimensional changes upon pouring delay and the inability to produce accurate casts

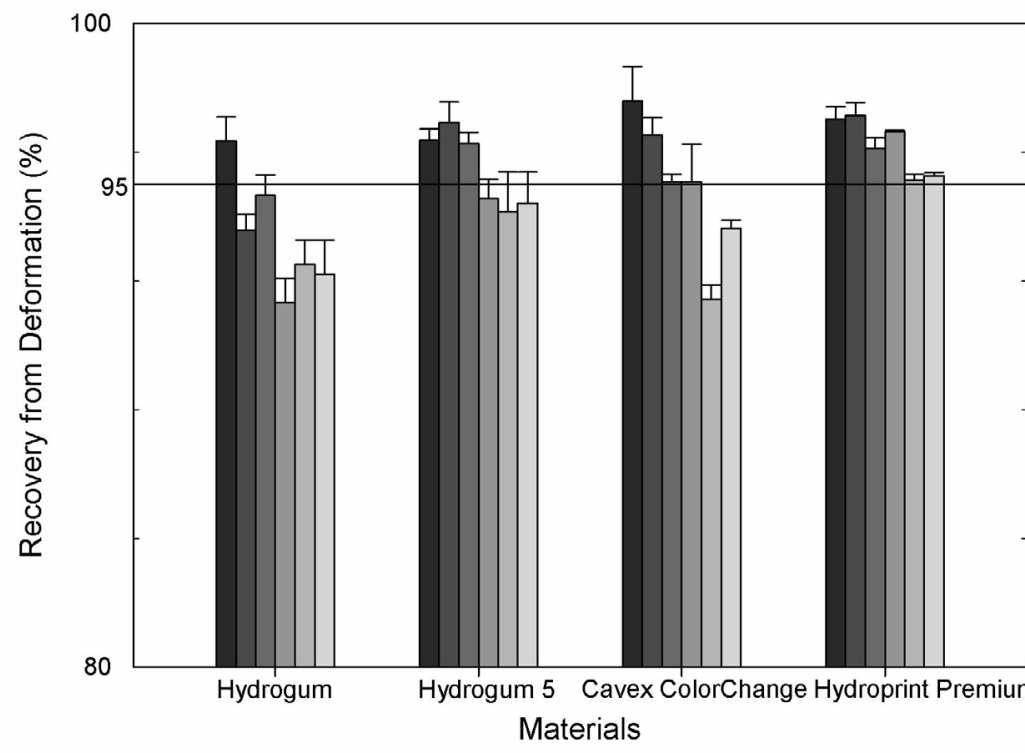

Figure 2 - Recovery from deformation values as a function of storage time (in days). The columns show the means and the bars indicate standard deviations. The reference bar represents the ADA no. 18 standard for recovery from deformation. 
Table 2 - Mean and standard deviation, in MPa, of the alginates' compressive strength values as a function of storage time, in days.

\begin{tabular}{c|c|c|c|c|c|c}
\hline & 0 & 1 & 2 & 3 & 4 & 5 \\
\hline Hydrogum 5 & $165.5 \pm 8.3^{\mathrm{C}, \mathrm{a}}$ & $213.4 \pm 11.4^{\mathrm{B}, \mathrm{c}}$ & $197.0 \pm 9.4^{\mathrm{B}, \mathrm{b}, \mathrm{c}}$ & $185.3 \pm 15.4^{\mathrm{B}, \mathrm{a}, \mathrm{b}}$ & $208.2 \pm 5.6^{\mathrm{B}, \mathrm{b}, \mathrm{c}}$ & $198.9 \pm 9.7^{\mathrm{B}, \mathrm{b}, \mathrm{c}}$ \\
\hline Hydrogum & $138.9 \pm 4.4^{\mathrm{B}, \mathrm{a}}$ & $227.8 \pm 5.2^{\mathrm{B}, \mathrm{b}}$ & $238.7 \pm 2.5^{\mathrm{C}, \mathrm{b}, \mathrm{c}}$ & $245.9 \pm 13.8^{\mathrm{C}, \mathrm{b}, \mathrm{c}}$ & $258.0 \pm 10.8^{\mathrm{C}, \mathrm{c}}$ & $245.6 \pm 9.5^{\mathrm{C}, \mathrm{b}, \mathrm{c}}$ \\
\hline Cavex ColorChange & $102.0 \pm 3.4^{\mathrm{A}, \mathrm{a}}$ & $134.1 \pm 16.2^{\mathrm{A}, \mathrm{b}}$ & $139.9 \pm 16.3^{\mathrm{A}, \mathrm{b}}$ & $126.1 \pm 7.8^{\mathrm{A}, \mathrm{a}, \mathrm{b}}$ & $149.1 \pm 17.7^{\mathrm{A}, \mathrm{b}}$ & $146.5 \pm 10.7^{\mathrm{A}, \mathrm{b}}$ \\
\hline Hydroprint & $196.9 \pm 12.1^{\mathrm{D}, \mathrm{a}}$ & $232.2 \pm 22.3^{\mathrm{B}, \mathrm{b}}$ & $254.7 \pm 15.5^{\mathrm{C}, \mathrm{b}, \mathrm{c}}$ & $267.1 \pm 5.4^{\mathrm{C}, \mathrm{c}, \mathrm{d}}$ & $294.3 \pm 3.4^{\mathrm{D}, \mathrm{d}}$ & $270.0 \pm 13.6^{\mathrm{C}, \mathrm{c}, \mathrm{d}}$ \\
\hline
\end{tabular}

Capital letters indicate significant difference in columns; small letters indicate significant difference in rows.

when the cast is repoured. ${ }^{10}$ In this study, delayed pouring negatively influenced the tested properties of irreversible hydrocolloids.

Compressive strength is an important property during the impression and production of cast models. When removed from the mouth, the material must possess sufficient strength to prevent ruptures and to ensure elastic recovery. ${ }^{11}$ Furthermore, the impression material should resist the weight of the gypsum without distortion. In this study, compressive strength values increased as storage time increased, even in a moist environment, for all irreversible hydrocolloids tested. One could expect that this finding shows an increase in material properties; however, the high compressive strength values could lead to a more rigid material, increasing the tearing risk when the cast is removed or subjected to compression. One of the reasons for this result could be the loss of water in the interior of the material, causing the collapse of the fibrillar cross-linked network $^{12}$ and leading to dimensional changes in the impression material. Cavex ColorChange displayed values higher than those illustrated in ANSI/ ADA specification no. 18-that is, the compressive strength should be at least $0.35 \mathrm{MPa}$. However, when compared to other brands, this compound exhibited lower values, which could be explained by the different proportions of the components within the compound. ${ }^{13}$

Dimensional changes in impression materials may arise from many possible causes, such as contraction due to syneresis, imbibition when exposed to water or a high-humidity environment, or incomplete recovery from deformation due to viscoelastic behavior. ${ }^{4}$ In this study, the dimensional stability of all materials tested decreased with increased storage time. This lack of stability was most likely a result of water gain or loss from the impression after setting to the environment. Imbibition (the absorption of fluid by a colloid, resulting in swelling), evaporation, and syneresis (the expulsion of a liquid from a gel) produce dimensional changes in the morphology of irreversible hydrocolloids. ${ }^{8}$ An impression with dimensional changes could lead to the misfit of prosthetic devices and decreased durability of treatments.

The effects of water evaporation and imbibition can be minimized by pouring the impression as soon as possible. Several studies have recommended immediate pouring or pouring within 10-15 minutes without wrapping in a wet towel to avoid any absorption of water by the material. ${ }^{14}$ Anseth et al. ${ }^{15}$ obtained the best results when dental alginate impressions were poured after 10 minutes to avoid distortion from the initial expansion and elastic deformation, but before 1 hour to avoid distortion of the alginate by contraction or expansion due to water imbibition and syneresis. However, new irreversible hydrocolloids appear to allow delayed pouring time for impressions without apparent significant effects. ${ }^{8}$ All materials tested in this study were able to maintain detail reproduction and gypsum compatibility after five days' storage time, but previous studies that evaluated the accuracy and dimensional stability of irreversible hydrocolloid impression materials have demonstrated the necessity of the immediate pouring of the material. ${ }^{16} \mathrm{~A}$ systematic review showed that shorter storage times before pouring are acceptable; ${ }^{8}$ however, no specific periods were described with respect to delays in pouring.

Despite the fact that irreversible hydrocolloids are hydrophilic materials, storage in a humid environment asserted no influence on the detail repro- 
duction and gypsum compatibility of alginate impressions, even after five days of storage. Another form of storage was tested in a study by Alcan et al., 5 who stored alginate impressions in sealed plastic bags without humidity for up to four days, which resulted in statistically significant deformation of the alginate impressions. In compliance with the manufacturer's instructions, the specimens in our study were stored in a moist environment in an attempt to avoid syneresis.

The impression requires elastic deformation as it is removed from the mouth; however, permanent deformation can be minimized if the material has a sufficiently high elastic limit. ${ }^{11}$ Only Hydro Print Premium and Hydrogum 5 obtained a recovery from deformation of $95 \%$ or more for all groups. The irreversible hydrocolloids may be stretched or compressed slightly, but they should not exhibit permanent deformation when removed. Hydrogum

\section{References}

1. Sedda M, Casarotto A, Raustia A, Borracchini A. Effect of storage time on the accuracy of casts made from different irreversible hydrocolloids. J Contemp Dent Pract. 2008 May;9(4):59-66.

2. Imbery TA, Nehring J, Janus C, Moon PC. Accuracy and dimensional stability of extended-pour and conventional alginate impression materials. J Am Dent Assoc. 2010 Jan;141(1):32-9.

3. Nandini VV, Venkatesh KV, Nair KC. Alginate impressions: A practical perspective. J Conserv Dent. 2008 JanMar;11(1):37-41.

4. Rishi D, Patel MTK, Charles J. Goodacre, Myron S. Winer MS. An in vitro investigation into the physical properties of irreversible hydrocolloid alternatives. J Prosthet Dent. 2010 Nov:104(5):325-32.

5. Alcan T, Ceylanoglu C, Baysal B. The relationship between digital model accuracy and time-dependent deformation of alginate impressions. Angle Orthod. 2009 Jan;79(1):30-6.

6. Tan HK, Wolfaardt JF, Hooper PM, Busby B. Effects of disinfecting irreversible hydrocolloid impressions on the resultant gypsum casts: Part I--Surface quality. J Prosthet Dent. 1993 Mar;69(3):250-7.

7. Jamani K. The effect of pouring time and storage condition on the accuracy of irreversible hydrocolloid impressions. Saudi Dent J. 2002 Sep-Dec;14(3):126-30.

8. Nassar U, Aziz T, Flores-Mir C. Dimensional stability of irreversible hydrocolloid impression materials as a function of pouring time: a systematic review. J Prosthet Dent. 2011 Aug;106(2):126-33. showed $95 \%$ recovery from deformation until the second day, and Color Change exhibited this amount of recovery until the third day.

It has been proposed that new alginates can be stored for up to five days; however, the results of this study demonstrated that only Hydrogum 5 can be stored for 24 hours without causing significant changes in its properties. Therefore, the standard procedure should be to cast immediately.

\section{Conclusions}

The results showed that irreversible hydrocolloids must be poured immediately.

\section{Acknowledgements}

The authors would like to express their thanks to the Brazilian Government through CAPES (Coordenação de Aperfeiçoamento de Pessoal de Nível Superior) for the financial support provided.

9. American Dental Association specification n. 18 for alginate impression materials. Chicago: American Dental Association; 1992. p.151-78. Available from: http://catalog.ada.org/ProductCatalog/688/Prosthodontic-Materials/ADA-Specification-No18-for-Dental-Alginate-Impression-Mater/ADA18-1992D.

10. Rubel BS. Impression materials: a comparative review of impression materials most commonly used in restorative dentistry. Dent Clin North Am. 2007 Jul;51(3):629-42.

11. Craig RG. Review of dental impression materials. Adv Dent Res. 1988 Aug;2(1):51-64.

12. Hondrum SO, Fernandez R Jr. Effects of long-term storage on properties of an alginate impression material. J Prosthet Dent. 1997 Jun;77(6):601-6.

13. Nallamuthu NA, Braden M, Patel MP. Some spects of the formulation of alginate dental impression materials - Setting characteristics and mechanical properties. Dent Mater. 2012 Jul;28(7):756-62.

14. Donovan TE, Chee WW. A review of contemporary impression materials and techniques. Dent Clin North Am. 2004 Apr;48(2):445-70.

15. Anseth KS, Bowman CN, Brannon-Peppas L. Mechanical properties of hydrogels and their experimental determination. Biomaterials. 1996 Sep;17(17):1647-57.

16. Vojdani M, Derafshi R. Evaluation of dimensional stability of Iralgin and Algino plast alginates after disinfection by sodium hypochlorite $(\% 5 / 2)$ with immersion and spraying methods. J Dent Med. 2006 Jan-Mar;18(4):87-94. 